\title{
Changes in Disease Resistance Phenotypes Associated With Plant Physiological Age Are Not Caused by Variation in $R$ Gene Transcript Abundance
}

\author{
Benjamin P. Millett, ${ }^{1}$ Dimitre S. Mollov, ${ }^{1}$ Massimo lorizzo, ${ }^{1,2}$ Domenico Carputo, ${ }^{2}$ and James M. Bradeen ${ }^{1}$ \\ ${ }^{1}$ Department of Plant Pathology, University of Minnesota, St. Paul, MN 55108 U.S.A.; ${ }^{2}$ Department of Soil, Plant, \\ Environmental and Animal Production Sciences, University of Naples "Federico II", Portici (NA), Italy
}

Submitted 11 July 2008. Accepted 5 November 2008.

Foliar late blight is one of the most important diseases of potato. Foliar blight resistance has been shown to change as a plant ages. In other pathosystems, resistance $(R)$ gene transcript levels appear to be correlated to disease resistance. The cloning of the broad-spectrum, foliar blight resistance gene $R B$ provided the opportunity to explore how foliar blight resistance and $\boldsymbol{R}$-gene transcript levels vary with plant age. Plants of Solanum bulbocastanum PT29, from which $R B$, including the native promoter and other flanking regions, was cloned, and $S$. tuberosum cv. Dark Red Norland (nontransformed and $R B$-transformed) representing three different developmental stages were screened for resistance to late blight and $R B$ transcript levels. Preflowering plants of all genotypes exhibited the highest levels of resistance, followed by postflowering and nearsenescing plants. The $R B$ transgene significantly affected resistance, enhancing resistance levels of all $R B$-containing lines, especially in younger plants. $R B$ transgene transcripts were detected at all plant ages, despite weak correlation with disease resistance. Consistent transcript levels in plants of different physiological ages with variable levels of disease resistance demonstrate that changes in disease-resistance phenotypes associated with plant age cannot be attributed to changes in $\boldsymbol{R}$-gene transcript abundance.

Pest and disease resistance in many plant species is affected by the growth stage of the plant (Abedon and Tracy 1996; Century et al. 1999; Hugot et al. 1999; Kolmer 1997; Martinez de Ilarduya and Kaloshian 2001). This may, in part, be mediated through changing source-sink relationships within the plant throughout development. In particular, development of storage organs and the coordinate shifting of energy away from other metabolic activities may alter disease resistance levels. Foliar late blight of potato (Solanum tuberosum L.) is one of the most destructive diseases of potato, responsible for multiple billions of dollars in losses annually worldwide (Kamoun 2001), but the effect of source-sink relationships on foliar late blight disease resistance is not entirely obvious. Some research suggests that resistance to late blight is highest at flowering, which approximately corresponds with the initiation of tuber development, and that both younger (preflowering) and older (postflowering or senescing) plants are less re-

Corresponding author: James M. Bradeen; E-mail: jbradeen@umn.edu

* The $\boldsymbol{e}$-Xtra logo stands for "electronic extra" and indicates that Figure 1 appears in color online. sistant (Carnegie and Colhoun 1982; Stewart 1990, Stewart et al. 1983a and b; Visker et al. 2003). Other researchers have observed that young (preflowering) potato plants that are susceptible to late blight actually become even more susceptible at the time of flowering (Carnegie and Colhoun 1982; Lowings and Acha 1959; Umaerus 1970). In these instances, disease resistance appears to decrease during sink formation, a trend similar to that noted for maize and tomato (Holbert et al. 1935; Horsfall and Heuberger 1942; Rowell 1953).

As expensive, prophylactic fungicides cannot guarantee complete protection of a potato field, breeders have looked to genetic resistance against Phytophthora infestans (Mont.) de Bary, the causal organism of late blight, for control of the disease. The best sources of late blight resistance are wild potato species, particularly those that originate in regions of the world with a long history of conducive environmental conditions for disease epidemics and genotypic diversity of P. infestans. One such region is the Toluca Valley of Mexico. Solanum bulbocastanum Dun., a potato species native to the Toluca Valley and surrounding regions, has been noted since at least 1939 for its high levels of blight resistance against all known races of $P$. infestans (Niederhauser and Mills 1953; Reddick 1939). Indeed, it is the source of three known late blight resistance genes, $R B$, Rpi-blb2, and Rpi-blb3 (Park et al. 2005; Song et al. 2003; van der Vossen et al. 2003, 2005). Although S. bulbocastanum is sexually isolated from cultivated potato (Haynes and Lu 2006), the recent cloning and transformation of $R B$, under control of its native promoter, into multiple $S$. tuberosum cultivars (Song et al. 2003, Bradeen et al. in press) has facilitated the study of its role in late blight resistance. A complete understanding of the role of $R B$ has been complicated by the $R B$ locus being responsible for only $62 \%$ of observed resistance (Naess et al. 2000) and by the presence of multiple homologs of $R B$ in at least three genome locations of $S$. bulbocastanum (Pan et al. 2000; Song et al. 2003), in addition to the aforementioned additional late blight resistance genes.

While late blight resistance at different potato plant physiological stages has been investigated for several decades, the cloning of late blight resistance genes now allows the study of how those specific genes affect disease development throughout different plant physiological stages. Understanding how plant physiological age impacts disease resistance is crucial for accurate late blight resistance screening and effective deployment of genetic resistance to late blight. In an effort to understand the effect of plant physiological age on $R B$ function and regulation, the current study screened multiple independently transformed lines of the potato cultivar Dark Red Norland, spanning different growth phases from preflowering to 
near-senescent, for foliar late blight resistance and transcript levels of the $R B$ transgene.

\section{RESULTS}

\section{Foliar blight assay.}

Four plants of each age (four, eight, and 12 weeks old) of each genotype (S. bulbocastanum PT29, S. tuberosum cv. Dark Red Norland nontransformed, and 'Dark Red Norland' $R B$ transformed lines SP2572, SP2577, and SP2585) were visually scored for disease development after inoculation with $P$. infestans in each experiment. Four-week-old plants were preflow-
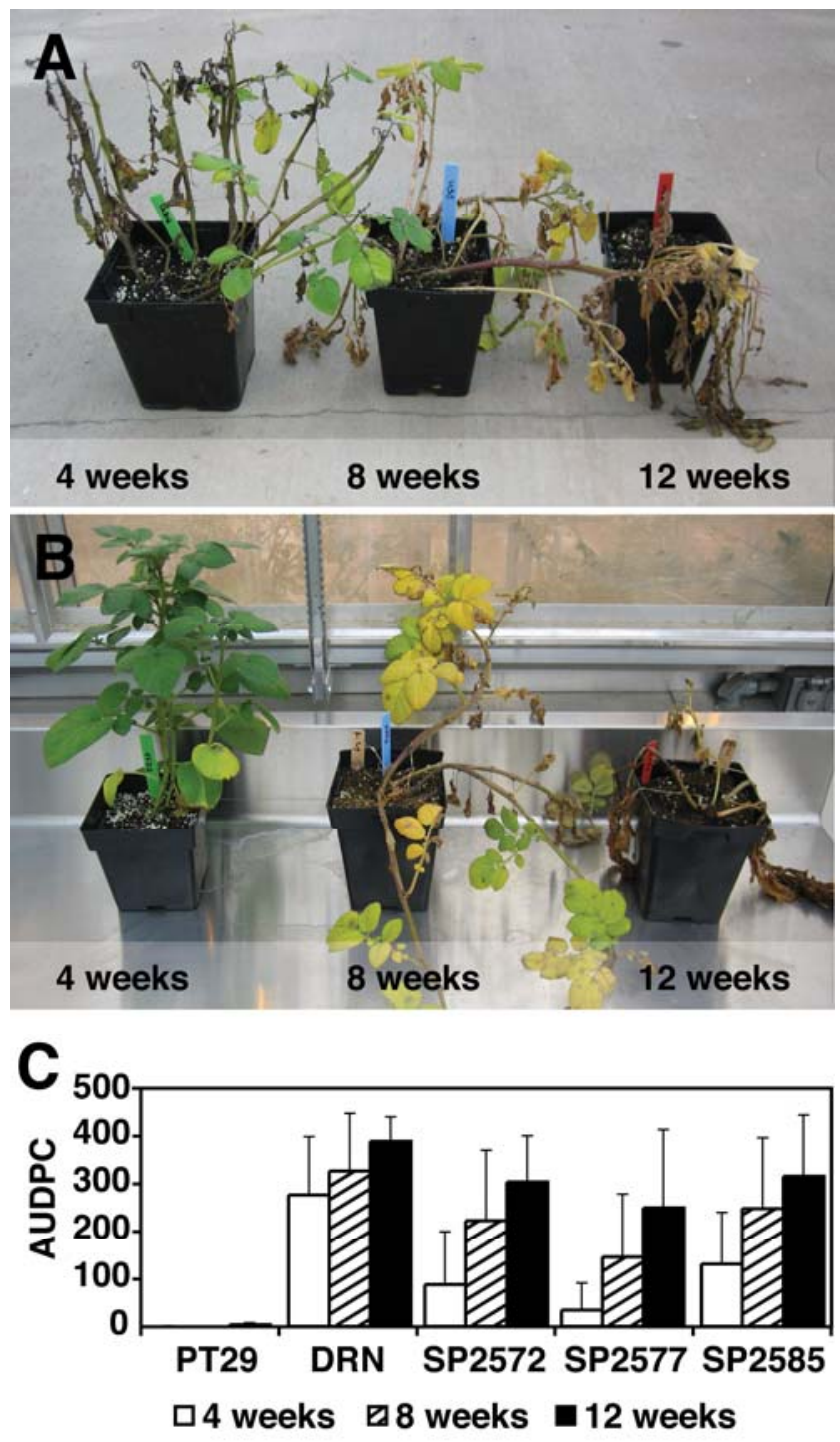

Fig. 1. Physiological age impacts disease development in both transformed and nontransformed plants. Solanum tuberosum cv. Dark Red Norland lines (nontransformed and $R B$ transgenic line SP2577) at four, eight, and 12 weeks after planting were inoculated with Phytophthora infestans US-8 and were subjected to environmental conditions conducive to late blight disease. Disease severity was visually assessed during the assay. A, Representative plants from each age group of nontransformed 'Dark Red Norland.' B, Representative plants from each age group of 'Dark Red Norland' $R B$ transgenic line SP2577. C, Area under the disease progress curve (AUDPC) values were determined for each plant between 4 and 9 days postinoculation and were averaged across trials within line and age. Error bars indicate standard deviations of those averages. In nontransformed (DRN) and transformed (SP2572, SP2577, and SP2585) 'Dark Red Norland' lines, AUDPC of each of the $R B$-transformed lines is less than nontransformed 'Dark Red Norland' of each physiological stage. ering and, presumably, had not yet begun to develop tubers. Eight-week-old plants had recently flowered and were in the early stages of tuber development. Twelve-week-old plants were very old, had completed tuber development, and were visibly senescing prior to inoculation.

Solanum bulbocastanum PT29 is thought to contain foliar blight resistance genes in addition to $R B$ (J. Bradeen, unpublished). As expected, PT29 plants of all age groups and across all trials remained green with few lesions (not shown). For cultivated potato, including nontransformed and transformed plants, physiological age visibly affected the rate of foliar late blight development (Fig. 1A and B). When species (S. bulbocastanum vs. $S$. tuberosum) was considered as a factor in analysis of variance (ANOVA), significant $(P<0.001)$ differences in rate of disease development were found (not shown), consistent with visual assessments (Fig. 1C). For S. tuberosum, although disease progression trends are generally consistent across trials, area under the disease progress curve (AUDPC) differed significantly $(P<0.001)$ between trials (Table 1$)$.

Importantly, consistent with visual assessment (Fig. 1), ANOVA revealed that plant age is a significant $(P<0.001)$ factor affecting AUDPC in $S$. tuberosum (Table 1). Indeed, in all trials, older (12-week-old) 'Dark Red Norland' plants with or without the $R B$ transgene were more susceptible to late blight than intermediately aged (eight-week-old) plants, which were, in turn, more susceptible than the youngest (four-weekold) plants (Fig. 1C).

While the different lines of 'Dark Red Norland' all exhibited blight development, the severity of disease was significantly $(P$ $<0.001)$ different. Nontransformed 'Dark Red Norland' plants were all clearly diseased; at the end of each experiment, the youngest plants (four weeks old) still had some green tissue and upright stems while the oldest plants (12 weeks old) were completely blighted (Fig. 1A). RB-transformed lines showed a similar pattern of decreasing resistance with increasing age (Fig. 1B), but the distinction between age classes was even more pronounced (Fig. 1C). At the end of the experiment, the youngest (four-week-old) transformed plants were still very green and had a full canopy of leaves, even though leaves did have some lesions. The leaves of the eight-week-old transformed plants were chlorotic, also with some blight lesions. The oldest (12-week-old) transformed 'Dark Red Norland' plants were completely dead by the end of each experiment. Not surprisingly, the presence of the transgene significantly $(P$ $<0.001)$ affected the AUDPC observed in the transgenic lines (Table 1). The observed greater resistance in younger plants as compared with older plants was significantly $(P<0.05)$ affected by the interaction of age and presence of the transgene (Table 1). This trend was observed in all trials. Importantly, the interaction between experimental trial and the presence of the $R B$ transgene was not significant $(P>0.05$; Table 1$)$. Taken together,

Table 1. Effect of trial, age, transgene presence, and line on the area under the disease progress curve for Solanum tuberosum lines ${ }^{\mathrm{a}}$

\begin{tabular}{lrrrc}
\hline & df $^{\mathbf{b}}$ & Mean Sq & $\boldsymbol{F}$ value & Significance $^{\mathbf{c}}$ \\
\hline Trial & 2 & 558,152 & 74.3714 & $* * *$ \\
Age & 1 & 911,869 & 121.5026 & $* * *$ \\
Transgene $(\mathrm{y} / \mathrm{n})$ & 1 & 583,278 & 77.7192 & $* * *$ \\
Line within transgene $(\mathrm{y} / \mathrm{n})$ & 2 & 83,921 & 11.1822 & $* * *$ \\
Trial $\times$ age & 2 & 41,330 & 5.5070 & $* *$ \\
Age $\times$ transgene $(\mathrm{y} / \mathrm{n})$ & 1 & 45,031 & 6.0002 & $*$ \\
Error & 134 & 7,505 & & \\
\hline
\end{tabular}

a Shown by analysis of variance. Nonsignificant two and three way interactions were removed from the model.

${ }^{\mathrm{b}} \mathrm{df}=$ degrees of freedom.

$\mathrm{c} * * *=$ significant at $0.001 ; * *=$ significant at $0.01 ; *=$ significant at 0.05 . 
these results indicate that the $R B$ transgene provided consistent disease resistance in all trials but that the effect of the transgene was greatest in younger tissues.

Line (independent transformation event) also had a significant $(P<0.001)$ effect on AUDPC (Table 1), consistent with previous observations of variation in resistance levels between independently transformed lines (Kuhl et al. 2007). Specifically, $R B$-transformed line SP2577 had a much greater range of disease development compared with the other transformed lines (Fig. 1C). This difference is supported by a Tukey significant $(P<0.05)$ difference in blight development between SP2577 and all other lines tested (PT29 and all other 'Dark Red Norland' lines). In all trials, the level of disease exhibited by the 12-week-old plants of all transformed lines was greater than or equal to those of the eight-week-old plants of the same line (Fig. 1C), consistent with the generalized trend of decreasing resistance with increasing plant age noted above.

\section{Quantitative reverse transcription-polymerase} chain reaction (qRT-PCR).

All genotypes tested for foliar blight development were also quantified for $R B$-transgene transcript levels. The RT-PCR assay used in this study is specific for the $R B$ transgene and can distinguish between the transgene and the endogenous $R B$ gene from which it was cloned, based on the presence of single nucleotide polymorphisms (SNP) specific to the transgene (Millett and Bradeen 2007). Accordingly, in none of the assays was transgene transcript detected in S. bulbocastanum PT29 or nontransformed 'Dark Red Norland', as expected (Fig. 2).

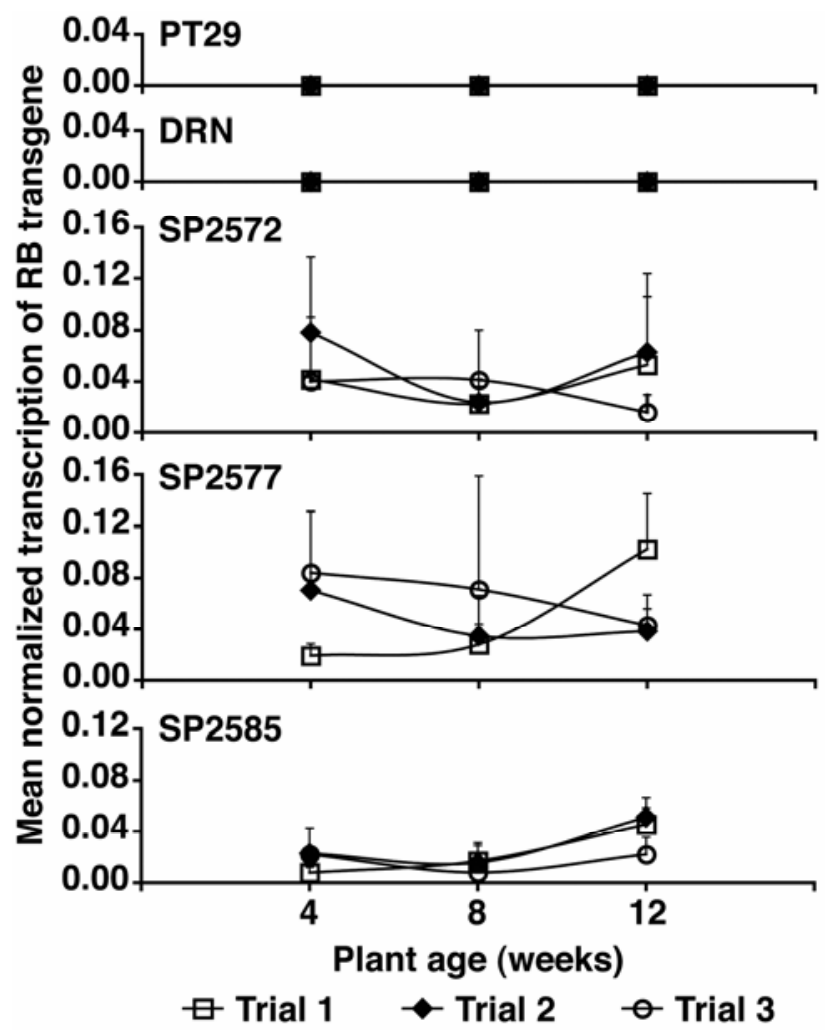

Fig. 2. $R B$ transgene transcript levels are stable in transgenic line SP2585. Average $R B$ transgene transcript levels (normalized to control EF1 $\alpha$ transcript levels) of three plants were assessed within $R B$-transformed lines SP2572, SP2577, and SP2585. RNA from three plants each of $S$. bulbocastanum PT29 and nontransformed 'Dark Red Norland' (DRN) was pooled by genotype and assessed for levels of $R B$ transgene transcript. Error bars reflect standard deviations of averaged transcript levels. The pattern of $R B$ transgene transcript levels between trials is most similar in transgenic SP2585.
Consistently, ANOVA revealed that both species (not shown) and presence of the transgene (Table 2$)$ have a significant $(P<$ $0.001)$ effect on $R B$-transgene transcript levels. As was true for AUDPC, line is a significant $(P<0.001)$ factor affecting $R B$ transgene transcript abundance, indicating that the level of $R B$ transcript is different in each independently transformed line. Trial also had a significant $(P<0.001)$ effect on levels of $R B$ transgene transcript. The source of trial-to-trial variation is not apparent but may be related to seed-tuber age or environmental variation (discussed below).

Surprisingly, although qRT-PCR technical replicates were consistent (demonstrated by low standard deviations [Fig. 2]), averaged across all experimental lines, significant $(P<0.001)$ variation in $R B$-transgene transcript between replicate plants within a transgenic line in the same experiment was noted. However, while replicate plant-to-replicate plant variability is evident for both SP2572 and SP2577 (four-week-old SP2577 plants were most variable, with a 66-fold difference in $R B$ transcript levels), no significant $(P>0.05)$ differences in $R B$ transcript levels were noted between individual SP2585 replicates (data not shown). Despite the inherent variation observed, Tukey significant $(P<0.05)$ differences in $R B$-transgene transcript abundance between plants at four and 12 weeks of age were evident for the transgenic lines SP2572 and SP2577. In contrast, for the less-variable SP2585 plants, no significant $(P>$ 0.05 ) differences in $R B$ transcript levels between plants of differing ages were noted (Fig. 2).

Next, the patterns of $R B$-transgene transcript abundance throughout plant development were explored. Preliminary exploratory data analyses of $R B$ transcript levels plotted against plant age suggested a nonlinear relationship (not shown). A linear factor, age, and a quadratic factor, age $^{2}$, were therefore included in statistical analyses of $R B$ transcript data. Both age and age $^{2}$ have significant $(P<0.05$ and $P<0.001$, respectively) effects on the transcript levels of the $R B$ transgene. The significant $(P<0.001)$ quadratic factor age ${ }^{2}$ in conjunction with its significant $(P<0.001)$ interaction with transgene presence suggests that the magnitude of difference of $R B$-transgene transcript levels varied with age of a plant.

Abundance of $R B$-transgene transcripts in all transformed lines in trials one and two is generally highest in the oldest (12-week-old) and youngest (four-week-old) plants and lowest in the middle-age (eight-week-old) plants. However, trial three shows a different pattern in levels of $R B$ transcript, with levels for lines SP2572 and SP2577 being comparatively high in the youngest (four-week-old) plants and lower in the oldest (12week-old) plants. These trends of age-variable transcript levels

Table 2. Effect of trial, age, transgene presence, line, and plant on $R B$ transgene transcript abundance for Solanum tuberosum lines ${ }^{\mathrm{a}}$

\begin{tabular}{lrccc}
\hline & $\mathbf{d f}^{\mathbf{b}}$ & Mean Sq & $\boldsymbol{F}$ value & Significance $^{\mathbf{c}}$ \\
\hline Trial & 2 & 0.001023 & 7.4453 & $* * *$ \\
Age & 1 & 0.000554 & 4.0372 & $*$ \\
Age $^{2}$ & 1 & 0.047997 & 349.4871 & $* * *$ \\
Transgene (y/n) & 1 & 0.056011 & 407.841 & $* * *$ \\
Line within transgene & 3 & 0.012114 & 88.2065 & $* * *$ \\
$(\mathrm{y} / \mathrm{n})$ & & & & \\
Plant within line within & & & & \\
$\quad$ transgene $(\mathrm{y} / \mathrm{n}))$ & 85 & 0.002905 & 21.1555 & $* * *$ \\
Trial $\times$ Age & 2 & 0.012256 & 89.2421 & $* * *$ \\
Trial $\times$ Age & 2 & 0.013793 & 100.4337 & $* * *$ \\
Age $^{2} \times$ Transgene $(\mathrm{y} / \mathrm{n})$ & 1 & 0.010666 & 77.6638 & $* * *$ \\
Error $^{2}$ & 198 & 0.000137 & & \\
\hline
\end{tabular}

a Shown by analysis of variance. Nonsignificant two way and three way interactions were removed from the model.

${ }^{\mathrm{b}} \mathrm{df}=$ degrees of freedom.

$\mathrm{c} * * *=$ significant at $0.001 ; * *=$ significant at $0.01 ; *=$ significant at 0.05 . 
suggest that the magnitude of $R B$-transgene transcript abundance differences between different plant ages for each trial is likely to be different, as both age and age $^{2}$ interact with the trial in a significant $(P<0.001)$ manner. This information is critical for sampling to ensure that differences of transcript levels between lines are accurately portrayed. Given the observed significant $(P<0.05)$ replicate plant-to-replicate plant variation in $R B$ transcript levels in lines SP2572 and SP2577, we are cautious to make firm conclusions about patterns of $R B$ transcript levels in these plants throughout development. In contrast, 'Dark Red Norland' line SP2585 has consistent $R B$ transcript values between replicate plants of the same age (data not shown) and between trials (Fig. 2). Not surprisingly, transcript levels of the $R B$ transgene in SP2585 are significantly $(P$ $<0.05)$ different from all other 'Dark Red Norland' lines in Tukey honestly significant difference (HSD) tests. As shown in Figure 2, abundance of $R B$-transgene transcript in line SP2585 also does not significantly $(P<0.05)$ vary throughout plant development. We conclude that for this particular line, plant physiological age has no significant $(P>0.05)$ impact on $R B$ transcript levels.

\section{$R B$ transgene transcript abundance weakly correlated with disease rating.}

The AUDPC of each line per age in each trial observed in the foliar-blight greenhouse assay was compared with its corresponding mean-normalized $R B$-transgene transcript value. Again, no $R B$-transgene transcript was observed, as expected, in S. bulbocastanum PT29 and the nontransformed 'Dark Red Norland', so no correlation could be made to the AUDPC. A polynomial line of best fit was applied to each transgenic line to account for the significant $(P<0.05$ and $P<0.001)$ effects of age and age $^{2}$, respectively, on transgene transcript levels. Two of the three transgenic lines in this study, lines SP2572 and SP2577, displayed significant $(P<0.05)$ replicate plantto-replicate plant variability in $R B$-transcript abundance, despite consistent disease-resistance phenotypes across replicates. For these lines, $\mathrm{R}^{2}$ values between $R B$ transcript levels and AUDPC were 0.0611 and 0.1734 , respectively. In contrast, transgenic line SP2585 had both consistent $R B$ transcript levels and consistent resistance phenotypes between replicate plants. Despite this reproducibility, $R B$ transcript levels and AUDPC were only weakly correlated $\left(\mathrm{R}^{2}=0.1771\right)$ in this line as well. These weak correlations suggest that, within these $R B$-transformed lines of 'Dark Red Norland', greater disease resistance may not be predictive of higher transgene transcript levels across multiple physiological ages. This conclusion is consistent with our observations of variable disease-resistance levels at different ages with essentially constant levels of $R B$ transcript in transgenic line SP2585.

\section{DISCUSSION}

We investigated $R B$-mediated late blight resistance and $R B$ transgene transcript levels of preflowering (four-week-old), postflowering (eight-week-old), and near-senescing (12-weekold) plants of cultivated and wild potato. Irrespective of transgene presence, the preflowering plants of all $S$. tuberosum genotypes exhibited greater resistance levels than the nearsenescing plants (Fig. 1C). Importantly, the transgene does have a significant $(P<0.001)$ effect on AUDPC (Table 1$)$, seen most clearly in the four- and eight-week-old plants of the transgenic lines compared with nontransformed 'Dark Red Norland'. Our findings that resistance to foliar late blight decreases as a potato plant ages and sets tubers parallel earlier observations of decreased disease resistance in sink-forming tomato and maize (Holbert et al. 1935; Horsfall and Heuberger 1942;
Rowell 1953). The youngest (four-week-old) potato plants in our study are presumed to have not yet begun developing tubers and therefore lacked a major sink, preserving metabolic energies for defense against pathogen attack. However, the eight-week-old plants had very recently finished flowering and were beginning to develop tubers. While the plants needed to defend themselves, they were also in the process of actively generating reproductive propagules, major energy sinks. As a result, the postflowering plants were less capable of mounting a defense response when inoculated with $P$. infestans. Although the oldest (12-week-old) plants had completed tuber development and were no longer diverting metabolic energies to a major sink, their natural senescence may have prevented a viable defense response, resulting in complete susceptibility, even in lines carrying the $R B$ transgene. Enhanced disease resistance at younger physiological ages (e.g., four- and eightweek-old plants) would presumably be of greater consequence to the survival of a genotype than disease resistance manifested in mature plants (e.g., 12-week-old plants).

Our results differ from the findings of Stewart (1990), Stewart and associates (1983a and b), and Visker and associates (2003) but are mostly consistent with those of Carnegie and Colhoun (1982). With the exception of Stewart (1990), who utilized detached-leaf assays, each of these research groups conducted whole-plant greenhouse tests of late blight resistance similar to those employed in our study. Stewart (1990), Stewart and associates (1983a and b), and Visker and associates (2003) assessed late blight resistance across plant ages, finding that potato plants were most resistant between weeks six and eight and were comparatively more susceptible at younger and older ages. The youngest plants tested by Stewart (1990) and Stewart and associates (1983a) were preflowering and were the most disease-susceptible. Stewart (1990) observed that resistance was highest during the early stages of flowering, which is a physiological age we did not assess. In contrast, Carnegie and Colhoun (1982), studying different potato genotypes, found that resistance was high in plants at the preflowering physiological age and continued to be high after flowering, until plants began to senesce. 'Dark Red Norland' was not used for any of these research studies, suggesting that the differences we observed in resistance trends across plant ages might be affected by genetic background. Additional screens of $R B$ transformed lines of 'Dark Red Norland' and other potato cultivars using narrower plant age intervals would provide a finer resolution of the importance of $R B$ in disease resistance and $R$ gene transcript levels throughout plant development. Because resistance phenotypes observed in greenhouse tests are well correlated to those of field evaluations $\left(\mathrm{R}^{2}=0.67\right.$ [J. Bradeen, unpublished] and 0.834 [Stewart et al. 1983a]), these data may have important impact on efforts to agriculturally deploy $R B$.

Significantly, patterns of disease resistance were identical in both nontransformed and transformed lines of 'Dark Red Norland' in our study. Thus, the trend of decreasing resistance with plant age cannot be a direct effect of the transgene $R B$. However, as the four-week-old plants of transformed lines are more resistant than those of the nontransformed lines, the addition of $R B$ enhances the resistance of the youngest plants.

Trial had a significant $(P<0.001)$ effect on both AUDPC and $R B$ transcript levels. The physiological age of the tubers used to generate the plants to be screened can affect disease resistance (Stewart et al. 1983a) and might also affect abundance of $R$ gene transcript. In the current study, the tubers planted in each experiment varied in age, with tubers planted for experiment three being more than a month older than those planted for experiment one. Tuber age and other variations between tubers planted, including tuber weight or size, could be evaluated for effect on $R B$ transcript levels. Additionally, it has 
been reported that time of year is an important factor affecting disease resistance levels (Lowings and Acha 1959; Stewart et al. 1983a; Visker et al. 2004), but effects on late blight $R$ gene transcript abundance have not been explored. It is possible that differences in transcript levels between trials in the current study may reflect changing environmental conditions resulting from seasonal changes. We are exploring the effects of varying environmental factors on levels of $R B$ transgene transcript in a series of parallel experiments.

One of the more interesting findings of the current study is that $R B$ transcript abundance between replicate plants of the same physiological age in lines SP2572 and SP2577 differed significantly $(P<0.05)$ while those of SP2585 did not. Plants within each line were clonally propagated and behaved similarly to each other in terms of late blight resistance. Each line represents an independent transformation event. As a result, the transgene was presumably introduced into the genome of 'Dark Red Norland' in varying locations. Recent work in Arabidopsis found that the endogenous copy of $S N C 1$, a toll interleukin 1 receptor-nucleotide binding site-leucine-rich repeat $R$ like gene, is transcribed at lower rates than when used as a transgene (with its native promoter) in the original Col accession (Li et al. 2007). Li and associates (2007) attribute this repression of the endogenous gene to chromatin structure or DNA methylation modification. Conversely, higher transcript levels as a transgene might suggest that the transgene is not under the same chromosomal structure repression as the endogenous gene. As a transgene in SP2572 and SP2577, $R B$ could have been introduced into a genome location at which transcript levels are affected to varying degrees in different replicate plants. In contrast, for SP2585, $R B$ could have been introduced into a region in which transcript levels are not easily altered, resulting in more consistent levels of $R B$ transcript between plants (Fig. 2). Given our results, future experiments detailing $R B$ transcript abundance should utilize transcript data averaged across multiple plants. Our findings suggest that more research aimed at understanding the impact of a transgene genomic position effect on transcript levels and phenotypic function is warranted.

In some pathosystems, strong correlations of disease resistance and $R$-gene transcript levels have been reported (Chintamanani et al. 2008; Li et al. 2007; Wang et al. 2007; Zuo et al. 2007). In each of these studies, disease resistance and $R$-gene transcript levels were measured at a single timepoint; variations due to changes in plant physiological age were not explored. For $R B$, a series of field trials independent of the research reported here suggests that disease resistance phenotypes of eight-week-old plants can be successfully predicted by $R B$ transcript levels (Bradeen et al. in press), consistent with a strong correlation between disease-resistance phenotype and $R$-gene transcript abundance at this particular plant age. As demonstrated in the current study, however, when the relationship between late blight resistance phenotypes and $R B$ transcript levels is examined across multiple plant physiological ages, a different picture emerges. For $R B$-transformed line SP2585, replicate plant-to-replicate plant variation was not significant for AUDPC or $R B$ transcript levels. Importantly, for this same line, stark differences in disease resistance phenotypes were noted for plants of different physiological ages (Fig. 1) but corresponding differences in $R B$ transcript levels were absent (Fig. 2). Together, these results demonstrate for the $R B$-late blight pathosystem that changes in plant-disease resistance phenotype associated with plant physiological age are not the result of changes in $R$-gene transcript levels.

Our conclusion is consistent with the results of Martinez de Ilarduya and Kaloshian (2001) and Chintamanani and associates (2008). In each of these cases, the researchers demonstrated developmentally regulated disease resistance without a concomitant change in levels of $R$-gene transcript. Martinez de Ilarduya and Kaloshian (2001) observed that the tomato $R$ gene $M i-1.2$, which imparts aphid resistance (Rossi et al. 1998), was transcribed at similar levels at different tomato plant ages (seedling or flowering stage). Despite Mi-1.2 transcription, however, seedlings were susceptible to aphids, whereas flowering plants were resistant. The pattern of resistance displayed by flowering tomato plants suggests that an additional component responsible for aphid-specific resistance is regulated by the developmental stage of the plant, as seedlings exhibit nematode-specific resistance imparted by Mi-1.2 (Martinez de Ilarduya and Kaloshian 2001). A similar pattern has been observed by Chintamanani and associates (2008) in maize. Resistance imparted by $\mathrm{Hm} 2$ of maize against Cochliobolus carbonum race 1 appears to steadily increase between two and 10 weeks of age, despite consistent transcript levels at all timepoints. In sum, results of Martinez de Ilarduya and Kaloshian (2001), Chintamanani and associates (2008), and the current study suggest that, in general, changes in disease resistance associated with plant age are not regulated by $R$-gene transcript abundance.

In interpreting our results, it is important to remember that detection of the $R B$ transcript does not necessarily signify that the gene product is translated and fully functional. It is possible that RB is present in the oldest plants but not at levels sufficient to impart the levels of resistance observed in the youngest (four-week-old) plants. Similar to the developmental differences found in $\mathrm{Mi}$-1.2-mediated resistance, the observed behavior of the $R B$ transgenic lines suggests that other factors that are impacted by the physiological age of the plants may be critical for $R B$-enhanced resistance to $P$. infestans. It is possible that certain components of the signaling pathway downstream of $R B$, such as homologs of NDR1 and EDS1, are not transcribed or exhibit decreased functionality as the plant matures. Bhaskar and associates (2008) have recently found that Sgt1silenced transgenic cultivated potato lines failed to exhibit $R B$ mediated resistance. Further investigation of $S g t 1$ and other downstream genes is warranted.

$R B$ triggers race-nonspecific resistance that, to date, has not been overcome by any known $P$. infestans race (Song et al. 2003). We have found, in this study examining three different physiological ages of $S$. tuberosum cv. Dark Red Norland, that the most resistant plants were those that were preflowering. $R B$ had a significant $(P<0.001)$ effect on late blight resistance by enhancing resistance levels of all $R B$-transformed lines. Additionally, we found in all transgenic lines that $R B$ is transcribed at all plant ages examined. Only one transgenic line, SP2585, yielded statistically stable estimates of $R B$ transcript levels in replicate plants. Importantly, while late blight resistance declined as SP2585 plants aged, $R B$ transcript levels remained constant. Consistent with observations for tomato Mil.2 (Martinez de Ilarduya and Kaloshian 2001) and maize Hm2 (Chintamanani et al. 2008), our data for the potato $R B$ foliar blight resistance gene demonstrate that changes in disease resistance phenotype as plants age are not attributable to changes in $R$ gene transcript abundance.

\section{MATERIALS AND METHODS}

\section{Plant material.}

Solanum bulbocastanum genotype PT29, cultivated potato carrying the $R B$ transgene ( $S$. tuberosum cv. Dark Red Norland [lines SP2572, SP2577, SP2585]), and nontransformed cultivated potato ( $S$. tuberosum cv. Dark Red Norland [clone of the parent used for transformation]) were gifts from J. Helgeson (United State Department of Agriculture-Agricultural Research 
Service and University of Wisconsin-Madison, U.S.A.) and S. Austin-Phillips (University of Wisconsin-Madison). All plant materials were produced in greenhouses on the University of Minnesota campus (St. Paul, MN, U.S.A.) using standard cultural practices. Plants were started from $50-\mathrm{g}$ seed pieces in LC8 growing media (soilless peat; Sun Gro Horticulture, Elma, Manitoba, Canada) and were fertilized once a week with NPK (20-20-20) at the rate of $200 \mathrm{mg} / \mathrm{kg}$. Plants were grown for four, eight, and 12 weeks, measured from the date the tuber was planted, and each line was represented by four plants at each age in each of three independent experiments (trial one, two, and three). Plants were grown at $24^{\circ} \mathrm{C}$ (day) and $15^{\circ} \mathrm{C}$ (night), 90\% relative humidity (RH), with artificial light employed to extend day length to $16 \mathrm{~h}$, under a light intensity of at least $80 \mathrm{~W} / \mathrm{m}^{2}$. For molecular assays, plant tissue (the third and fourth fully expanded leaves below the crown of the plant) was excised from plants immediately prior to inoculation and was frozen in liquid nitrogen and stored at $-80^{\circ} \mathrm{C}$.

\section{Foliar blight assay.}

Approximately two weeks prior to inoculation in each experiment, $P$. infestans US-8 (isolate 940480 [A2]) sporangia were harvested in sterile distilled $\mathrm{H}_{2} \mathrm{O}$ from cultures growing on rye agar dextrose plates at $18^{\circ} \mathrm{C}$. Sporangia were stored for $60 \mathrm{~min}$ at $4^{\circ} \mathrm{C}$, followed by $30 \mathrm{~min}$ at room temperature. Leaves of foliar late blight-susceptible $S$. tuberosum were removed from greenhouse-grown plants, and the cut stems were submersed in sterile $\mathrm{H}_{2} \mathrm{O}$. The leaves were inoculated to runoff by misting with $P$. infestans sporangia. Inoculated leaves were maintained under high humidity in chambers at $18^{\circ} \mathrm{C}$. On the day of inoculation in each experiment, the diseased leaves were washed in sterile distilled $\mathrm{H}_{2} \mathrm{O}$ and the collected sporangia were diluted to 1,000 sporangia per milliter of $\mathrm{H}_{2} \mathrm{O}$ and were stored for $60 \mathrm{~min}$ at $4^{\circ} \mathrm{C}$, followed by $30 \mathrm{~min}$ at room temperature. Experimental plants were arranged randomly by age and genotype on raised greenhouse beds in a complete random design. Plant leaves were misted to runoff with inoculum and were maintained at 18 to $21^{\circ} \mathrm{C}$ during the day and 15 to $18^{\circ} \mathrm{C}$ at night. A fog system maintained humidity at $\geq 90 \%$ RH. Disease development was visually assessed (scale of 1 to 9 [Henfling 1979]) every day for six days after the first symptoms appeared (approximately 4 days postinoculation). Scores were read in February and March 2006 for all trials (February 6 through 13 for trial one, February 20 through 27 for trial two, and March 4 through 9 for trial three). AUDPC between days 4 and 9 postinoculation was determined for each plant, as described by Shaner and Finney (1977).

Results were analyzed by ANOVA and Tukey HSD using R for Mac OS X, GUI v1.22-devel (The R Foundation for Statistical Computing, Vienna, Austria).

\section{Primer design.}

$R B$ transgene-specific primers 2MAMA5'3 (forward, TTGC AACCATATGAACTGTCAACC, melting temperature $(\mathrm{Tm})=$ $63.17^{\circ} \mathrm{C}$ ) and $2 \mathrm{MAMA}^{\prime} 1$ (reverse, CCAGAGAGAGATTAGC TTTTCTTTTCT, $\mathrm{Tm}=60.39^{\circ} \mathrm{C}$ ) were developed previously (Millett and Bradeen 2007). Briefly, three SNP having no obvious phenotypic effect were introduced into the $R B$ coding region when $R B$ was cloned via long-range PCR (Song et al. 2003). To develop PCR and RT-PCR assays specific for the $R B$ transgene, two of these SNP were targeted, using the concept of mismatch amplification mutation assay (Cha et al. 1992), to develop primers that only amplify the transgene to the complete exclusion of the native $R B$ allele and each of its multiple homologs found in $S$. tuberosum and $S$. bulbocastanum. Nicot and associates (2005) demonstrated that Elongation Factor 1$\alpha(E F 1 \alpha)$ is an appropriate control for real-time RT-PCR ex- periments of potato- $P$. infestans interactions. We adopted the $E F 1 \alpha$ primers developed by these authors (EF1-f [forward, ATTGGAAACGGATATGCTCCA, Tm $\left.=61.56^{\circ} \mathrm{C}\right]$ and EF1-r [reverse, TCCTTACCTGAACGCCTGTCA, Tm $\left.=63.03^{\circ} \mathrm{C}\right]$ ). All primers were obtained from Integrated DNA Technologies (Coralville, IA, U.S.A.).

\section{qRT-PCR methods.}

Total RNA was extracted from frozen tissues (leaves collected from the same plant were ground together), using the SV total RNA isolation kit (Promega, Madison, WI, U.S.A.) according to manufacturer's recommendations. RNA samples were quantified with a NanoDrop ND-1000 (NanoDrop Technologies, LLC, Wilmington, DE, U.S.A.).

qRT-PCR assays were performed using SuperScript III platinum SYBR green one-step qRT-PCR kit with ROX (Invitrogen, Carlsbad, CA, U.S.A.) in a $25-\mu l$ total volume, following manufacturer's recommendations, using $5 \mu \mathrm{l}(7$ to $50 \mu \mathrm{M})$ of template. Primers were tested at varying concentrations, extension times, and temperatures. Those primers targeting $R B$ were used at final concentrations of $200 \mathrm{nM}$ (forward) and $900 \mathrm{nM}$ (reverse), while both $E F 1 \alpha$ primers were at $400 \mathrm{nM}$. $R B$ and $E F 1 \alpha$ fragments were amplified in independent reaction tubes. Each RNA sample was tested in triplicate. An Applied Biosystems 7500 real-time PCR system (Foster City, CA, U.S.A.) was utilized for all real-time assays. All qRT-PCR assays underwent an initial RT cycle $\left(30 \mathrm{~min}\right.$ at $\left.50^{\circ} \mathrm{C}\right)$ and denaturing step ( 2 min at $94^{\circ} \mathrm{C}$ ). Reactions evaluating $R B$ transcript levels continued with 40 cycles of $94^{\circ} \mathrm{C}$ for $15 \mathrm{~s}, 57^{\circ} \mathrm{C}$ for $28 \mathrm{~s}$, and $72^{\circ} \mathrm{C}$ for $32 \mathrm{~s}$. Internal control EFI $\alpha$ reactions used 40 cycles of $94^{\circ} \mathrm{C}$ for $15 \mathrm{~s}$ and $60^{\circ} \mathrm{C}$ for $60 \mathrm{~s}$. All reactions concluded with a melting curve evaluation. Results were evaluated using Sequence Detection Software v. 1.4.0.25 (Applied Biosystems). The threshold value was adjusted against control reactions for consistent cycle threshold $\left(\mathrm{C}_{\mathrm{t}}\right)$ values across multiple experimental plates. $\mathrm{C}_{\mathrm{t}}$ values for the $R B$ transgene and $E F 1 \alpha$ were then processed with the visual basic software Q-Gene (Muller et al. 2002) in Microsoft Excel for Mac 2004 (v11.3.7; Microsoft Corp., Redmond, WA, U.S.A.) and were subsequently analyzed by ANOVA and Tukey HSD using R for Mac OS X, GUI v1.22-devel. Correlations of phenotypic and transcript data were performed in Microsoft Excel for Mac.

During initial testing of primers under qRT-PCR conditions, amplification product size was verified by separation on $1 \%$ agarose gels in tris-borate-EDTA buffer, staining with ethidium bromide, and photographing under UV light. Amplicons were compared with DNA standards of known size. All nucleotide sequences were verified using Applied Biosystems BigDye terminator (v. 3.1) cycle sequencing on an Applied Biosystems $3130 x 1$ or $3730 x 1$ at the University of Minnesota BioMedical Genomics Center. PCR samples were sequenced directly, using 3.2 pmole of the appropriate gene-specific forward (2MAMA5'3 or EF1-f) or reverse (2MAMA3'1 or EF1-r) primer. Sequences were analyzed and assembled into contigs using SeqMan Pro (Windows Server 2003 SP2, v. 7.1.0; DNASTAR Inc, Madison, WI, U.S.A.). Homology of the contigs to known sequences was determined using BLASTn (National Center for Biotechnology Information).

\section{ACKNOWLEDGMENTS}

The authors thank J. Helgeson, J. Jiang, and S. Austin-Phillips for plant materials. Guidance by S. McKay in statistical analyses and the computer support from the University of Minnesota Supercomputing Institute are gratefully acknowledged. This research was funded in part by a National Science Foundation Graduate Research Fellowship to B. P. Millett. This is contribution no. 176 from the Department of Soil, Plant, Environmental and Animal Production Sciences. 


\section{LITERATURE CITED}

Abedon, B. G., and Tracy, W. F. 1996. Corngrass1 of maize (Zea mays L.) delays development of adult plant resistance to common rust (Puccinia sorghi Schw.) and European corn borer (Ostrinia nubilalis Hubner). J. Hered. 87:219-223.

Bhaskar, P. B., Raasch, J. A., Kramer, L. C., Neumann, P., Wielgus, S. M., Austin-Phillips, S., and Jiang, J. 2008. Sgt1, but not Rar1, is essential for the $R B$-mediated broad-spectrum resistance to potato late blight. BMC Plant Biol 8:8.

Bradeen, J. M., Iorizzo, M., Mollov, D. S., Raasch, J., Kramer, L. C., Millett, B. P., Austin-Phillips, S., Jiang, J., and Carputo, D. Higher copy numbers of the potato $R B$ transgene correspond to enhanced transcript and late blight resistance levels. Mol. Plant-Microbe Interact. In press.

Carnegie, S. F., and Colhoun, J. 1982. Susceptibility of potato leaves to Phytophthora infestans in relation to plant age and leaf position. Phytopath. Z. 104:157-167.

Century, K. S., Lagman, R. A., Adkisson, M., Morlan, J., Tobias, R., Schwartz, K., Smith, A., Love, J., Ronald, P. C., and Whalen, M. C. 1999. Developmental control of Xa21-mediated disease resistance in rice. Plant J. 20:231-236.

Cha, R. S., Zarbl, H., Keohavong, P., and Thilly, W. G. 1992. Mismatch amplification mutation assay (MAMA): Application to the c-H-ras gene. PCR Meth. Appl. 2:14-20.

Chintamanani, S., Multani, D. S., Ruess, H., and Johal, G. S. 2008. Distinct mechanisms govern the dosage-dependent and developmentally regulated resistance conferred by the maize $\mathrm{Hm} 2$ gene. Mol. Plant-Microbe Interact. 21:79-86.

Haynes, K. G., and Lu, W. 2006. Improvement at the diploid species level. Pages 101-114. In: Genetic Improvement of Solanaceous Crops, Vol. 1: "Potato". M. K. Razdan and A. K. Mattoo, eds. Science Publishers, Inc., Enfield, NH. U.S.A.

Henfling, J. W. 1979. Late blight of potato: Phytophthora infestans. Page 13. In: Technical Information Bulletin. International Potato Center, Lima, Peru.

Holbert, J. R., Hoppe, P. E., and Smith, A. L. 1935. Some factors affecting infection with and spread of Diplodia zeae in host tissue. Phytopathology 25:1113-1114.

Horsfall, J. G., and Heuberger, J. W. 1942. Pages 182-183 in: Causes, effects, and control of defoliation on tomatoes. Conn. Agric. Exp. Stn. Bull. 456. New Haven, CT. U.S.A.

Hugot, K., Aimé, S., Conrod, S., Poupet, A., and Galiana, E. 1999. Developmental regulated mechanisms affect the ability of a fungal pathogen to infect and colonize tobacco leaves. Plant J. 20:163-170.

Kamoun, S. 2001. Nonhost resistance to Phytophthora: Novel prospects for a classical problem. Curr. Opin. Plant Biol. 4:295-300.

Kolmer, J. A. 1997. Virulence in Puccinia recondita f. sp. tritici isolates from Canada to genes for adult-plant resistance to wheat leaf rust. Plant Dis. 81:267-271.

Kuhl, J. C., Zarka, K., Coombs, J., Kirk, W. W., and Douches, D. S. 2007. Late blight resistance of $R B$ transgenic potato lines. J. Amer. Soc. Hort. Sci. 132:783-789.

Li, Y., Yang, S., Yang, H., and Hua, J. 2007. The TIR-NB-LRR gene SNC1 is regulated at the transcript level by multiple factors. Mol. Plant-Microbe Interact. 20:1449-1456.

Lowings, P. H., and Acha, I. G. 1959. Some factors affecting growth of Phytophthora infestans (Mont.) de Bary. Trans. Br. Mycol. Soc. 42:491501 .

Martinez de Ilarduya, O., and Kaloshian, I. 2001. MI-1.2 transcripts accumulate ubiquitously in resistant Lycopersicon esculentum. J. Nematol. 33:116-120.

Millett, B., and Bradeen, J. 2007. Development of allele-specific PCR and RT-PCR assays for clustered resistance genes using a potato late blight resistance transgene as a model. Theor. Appl. Genet. 114:501-513.

Muller, P. Y., Janovjak, H., Miserez, A. R., and Dobbie, Z. 2002. Processing of gene expression data generated by quantitative real-time RTPCR. BioTechniques 32:1372-1379.

Naess, S. K., Bradeen, J. M., Wielgus, S. M., Haberlach, G. T., McGrath,
J. M., and Helgeson, J. P. 2000. Resistance to late blight in Solanum bulbocastanum is mapped to chromosome 8. Theor. Appl. Genet. 101:697-704.

Nicot, N., Hausman, J.-F., Hoffmann, L., and Evers, D. 2005. Housekeeping gene selection for real-time RT-PCR normalization in potato during biotic and abiotic stress. J. Exp. Bot. 56:2907-2914.

Niederhauser, J. S., and Mills, W. R. 1953. Resistance of Solanum species to Phytophthora infestans in Mexico. Phytopathology 43:456-457.

Pan, Q., Liu, Y. S., Budai-Hadrian, O., Sela, M., Carmel-Goren, L., Zamir, D., and Fluhr, R. 2000. Comparative genetics of nucleotide binding site-leucine rich repeat resistance gene homologues in the genomes of two dicotyledons: Tomato and arabidopsis. Genetics 155:309-322.

Park, T.-H., Gros, J., Sikkema, A., Vleeshouwers, V. G. A. A., Muskens, M., Allefs, S., Jacobsen, E., Visser, R. G., and van der Vossen, E. A. G. 2005. The late blight resistance locus Rpi-bib3 from Solanum bulbocastanum belongs to a major late blight $R$ gene cluster on chromosome 4 of potato. Mol. Plant-Microbe Interact. 18:722-729.

Reddick, D. 1939. Whence came Phytophthora infestans? Chron. Bot. 5:410-412.

Rossi, M., Goggin, F. L., Milligan, S. B., Kaloshian, I., Ullman, D. E., and Williamson, V. M. 1998. The nematode resistance gene $M i$ of tomato confers resistance against the potato aphid. Proc. Natl. Acad. Sci. U.S.A. 95:9750-9754.

Rowell, J. B. 1953. Leaf blight of tomato and. potato plants. R. I. Agrie. Exp. Stn. Bull. 320:1-29.

Shaner, G., and Finney, R. A. 1977. The effect of nitrogen fertilization on the expression of slow-mildewing resistance in Knox wheat. Phytopathology 67:1051-1056.

Song, J., Bradeen, J. M., Naess, S. K., Raasch, J. A., Wielgus, S. M., Haberlach, G. T., Liu, J., Kuang, H., Austin-Phillips, S., Buell, C. R., Helgeson, J. P., and Jiang, J. 2003. Gene $R B$ cloned from Solanum bulbocastanum confers broad spectrum resistance to potato late blight. Proc. Natl. Acad. Sci. U.S.A. 100:9128-9133.

Stewart, H. E. 1990. Effect of plant age and inoculum concentration on expression of major gene resistance to Phytophthora infestans in detached potato leaflets. Mycol. Res. 94:823-826.

Stewart, H. E., Flavelle, P. H., McCalmont, D. C., and Wastie, R. L. 1983a Correlation between glasshouse and field tests for resistance to foliage blight caused by Phytophthora infestans. Potato Res. 26:41-48.

Stewart, H. E., Taylor, K., and Wastie, R. L. 1983b. Resistance to late blight in foliage (Phytophthora infestans) of potatoes assessed as true seedlings and as adult plants in the greenhouse. Potato Res. 26:363-366.

Umaerus, V. 1970. Studies on field resistance to Phythophthora infestans 5. Mechanisms of resistance and application to potato breeding. Z PflZücht. 63:1-23.

van der Vossen, E., Sikkema, A., te Lintel Hekkert, B., Gros, J., Stevens, P., Muskens, M., Wouters, D., Pereira, A., Stiekema, W., and Allefs, S. 2003. An ancient R gene from the wild potato species Solanum bulbocastanum confers broad-spectrum resistance to Phytophthora infestans in cultivated potato and tomato. Plant J. 36:867-882.

van der Vossen, E. A., Gros, J., Sikkema, A., Muskens, M., Wouters, D., Wolters, P., Pereira, A., and Allefs, S. 2005. The Rpi-blb2 gene from Solanum bulbocastanum is an $\mathrm{Mi}-1$ gene homolog conferring broad-spectrum late blight resistance in potato. Plant J. 44:208-222.

Visker, M. H. P. W., Keizer, L. C. P., Budding, D. J., van Loon, L. C., Colon, L. T., and Struik, P. C. 2003. Leaf position prevails over plant age and leaf age in reflecting resistance to late blight in potato. Phytopathology 93:666-674.

Visker, M. H. P. W., van Raaij, H. M. G., Keizer, L. C. P., Struik, P. C., and Colon, L. T. 2004. Correlation between late blight resistance and foliage maturity type in potato. Euphytica 137:311-323.

Wang, W., Devoto, A., Turner, J. G., and Xiao, S. 2007. Expression of the membrane-associated resistance protein RPW8 enhances basal defense against biotrophic pathogens. Mol. Plant-Microbe Interact. 20:966-976.

Zuo, K.-J., Qin, J., Zhao, J.-Y., Ling, H., Zhang, L.-D., Cao, Y.-F., and Tang, K.-X. 2007. Over-expression GbERF2 transcription factor in tobacco enhances brown spots disease resistance by activating expression of downstream genes. Gene 391:80-90. 